This study won the ML Roberts Prize, awarded for the best fourth year undergraduate research project at the School of Physiotherapy, University of Otago in 2018.

\title{
Attitudes of healthcare professionals towards self-management for patients with stroke
}

Ashleigh Taylor* BPhty

School of Physiotherapy, University of Otago, Dunedin, New Zealand

Xavier Monsanto* BPhty

School of Physiotherapy, University of Otago, Dunedin, New Zealand

Hayden Kilgour* BPhty

School of Physiotherapy, University of Otago, Dunedin, New Zealand

Catherine Smith Dip PT, PhD

Lecturer, School of Physiotherapy, Centre for Health, Activity and Rehabilitation Research, University of Otago, Dunedin, New Zealand

Leigh Hale BSC (Physio), MSc, PhD, FNZCP

Dean, School of Physiotherapy, Centre for Health, Activity and Rehabilitation Research, University of Otago, Dunedin, New Zealand

*Undergraduate students at the time of the study.

\section{ABSTRACT}

Self-management approaches towards stroke rehabilitation are gaining more attention due to emerging evidence of their impact on patient outcomes. This mixed methods study explored the attitudes of healthcare professionals (HCPs) towards stroke selfmanagement. The Bridges Stroke Self-Management Programme (Bridges SSMP) training was delivered to 51 HCPs in New Zealand. Questionnaires were completed by consenting participants $(n=43)$ prior to administration of the Bridges SSMP training. In-depth, semi-structured interviews were conducted with three participants. The General Inductive Approach was used for thematic analysis of the qualitative data. The resulting overarching theme was "integrating the self-management concept into practice", which encompasses organisational, contextual and individual factors that HCPs feel are challenges when applying self-management. Two contributors to this theme - "education" and "facilitating empowerment" - emerged as barriers or enablers, respectively, to putting self-management into practice. Questionnaire data showed HCPs were confident in their capability of self-management concepts yet did not frequently use them in practice. Healthcare professionals were mostly positive about the concept of self-management but challenges and barriers were evident when applying this to practice. Hence, they may require a deeper understanding of the principles of self-management and become more familiar with the process by applying the principles of self-management in their own lives.

\section{Taylor, A., Monsanto, X., Kilgour, H., Smith, C., \& Hale, L. (2019). Attitudes of healthcare professionals towards self- management for patients with stroke. New Zealand Journal of Physiotherapy, 47(1), 25-35. https://doi.org/10.15619/ NZJP/47.1.04}

Key Words: Stroke, Self-management, New Zealand, Healthcare Professionals, Rehabilitation, Self-efficacy

\section{INTRODUCTION}

Stroke is the third most common cause of disability globally, with incidence remaining high in New Zealand (Valery, Bo, \& George, 2017). Stroke has an impact on an individual's ability to carry out activities of daily living and participate in life roles, and this places a burden on health and social care (Rajsic et al., 2019). Self-management is a concept that has received increased attention in stroke rehabilitation, encouraging individuals to take charge of and become independent in managing their lives following stroke (Jones, Riazi, \& Norris, 2013). Approaches to the management of long-term conditions have traditionally been led by healthcare professionals (HCPs), but contemporary strategies are moving away from this model. Self-management approaches, where individuals play an important role in managing their own condition while engaging in a partnership and guidance from professionals, are gaining more interest in clinical practice (Lorig \& Holman, 2003). Self-management can be defined as an "individual's ability to manage the symptoms, treatment, physical and psychosocial consequences and lifestyle changes inherent in living with a chronic condition" (Barlow, Wright, Sheasby, Turner, \& Hainsworth, 2002, p.178). Principles of self-management include problem-solving, goal setting, decision-making, reflection, knowledge, collaboration and taking action (Jones, Pöstges, \& Brimicombe, 2016)

The Bridges Stroke Self-Management Programme (Bridges SSMP) is an individualised programme that was developed in the United Kingdom and is based on the principles of self-efficacy 
as described in the Social Cognitive Theory (Jones, Mandy, \& Partridge, 2009). This theory describes self-efficacy as an individual's belief in their own ability; interventions based on this theory aim to increase a person's self-efficacy to manage their own health or recovery and tend to include goal setting, self-led activity and skills training as components (Jones et al., 2009). The Bridges SSMP trains HCPs in ways to build self-efficacy and self-management skills in the patients they work with, enabling patients to take charge of their own recovery following stroke (Jones et al., 2009).

The skills of self-management are distinct and far more extensive than just patient education, which is a core skill of HCPs. Therefore, it is important to consider the attitudes, knowledge and beliefs of HCPs towards self-management when considering the implementation of this approach in stroke rehabilitation. A previous study that explored the attitudes of HCPs towards stroke self-management found that whilst stroke practitioners were positive about the Bridges SSMP and were willing to apply the principles of this approach to their practice, there were challenges and barriers to its implementation (Jones \& Bailey, 2013). Identified barriers were lack of time, patients moving quickly between healthcare teams and the influence of the acute setting. A qualitative study by Satink, Cup, de Swart, \& Nijhuis-van der Sanden (2015) identified "patient" barriers including the capacity for the patient to be able to self-manage due to factors such as altered cognitive abilities, insight and awareness of problems. Healthcare professionals also questioned whether their own attitudes and skill set were complementary to the promotion of self-management. For example, HCPs felt they often did too much for the patient when working alongside those with stroke, and did not give patients a chance to manage the situation by themselves (Satink et al., 2015).

Previous studies on the attitudes of HCPs towards stroke selfmanagement have been conducted in the United Kingdom and the Netherlands (Jones \& Bailey, 2013; Satink et al., 2015). However, in New Zealand, the attitudes of HCPs are unknown as the Bridges SSMP is still in the early stages of implementation and little research has been done in this area. The aim of this study was to explore the attitudes, knowledge and beliefs of HCPs towards stroke self-management in New Zealand in order to inform professionals implementing self-management into stroke rehabilitation.

\section{METHODS}

\section{Study design}

A mixed methods study, involving both qualitative and quantitative data, was undertaken to gain an understanding of the attitudes of HCPs towards stroke self-management. Qualitative data comprised the core component related to our enquiry and was supplemented by the quantitative data. This approach was taken to provide a richer, deeper and better understanding of the important facets of the attitudes towards self-management (Morse, 2009). Ethical approval was gained from the Health and Disability Ethics Committees, Ministry of Health, New Zealand (reference number 18/STH/93). All included participants gave written informed consent before completing questionnaires and participating in in-depth interviews.

\section{Participants and procedures}

Bridges SSMP training is delivered in two parts, a full-day workshop followed by a half-day workshop four to six months later. In the workshops, key principles of self-management are emphasised and reinforced. For example, self-management approaches need to be specifically "tailored" to the individual so building personal knowledge becomes more important than delivering generic education. In the period between the two workshops, practitioner support is offered whilst the skills learnt in the initial workshop are implemented into practice. Data for this study were collected following the initial workshop delivered to 51 HCPs in New Zealand. Two questionnaires were completed by consenting participants prior to the initial workshop. Based on the total scores from one questionnaire, three consenting participants were purposefully sampled for in-depth, semistructured interviews. Sampling captured a range of attitudes to patient self-management identified from the questionnaire data.

\section{Evaluation}

Both of the questionnaires were developed by Jones and Bailey (2013) to explore the experiences and perceptions of stroke practitioners about the stroke pathway and self-management. These questionnaires were based on the seven key principles of the Bridges SSMP: problem-solving, reflection, goal setting, accessing resources, self-discovery, activity and knowledge (Jones et al., 2016).

Questionnaire 1: The first section of questionnaire 1 had two parts. Part A was designed to assess participants' view of their current capability to deliver self-management concepts (questions 1-15a). A five-point Likert scale was used, and participants were asked to rate their ability to carry out statements related to self-management, for example zero being "not at all" and four being "good". Participants were then asked to rate the frequency at which they implemented the task or concept (Part B) (questions 1-15b). A five-point Likert scale was also used, with zero being "never" and four being "always". A second section was included which assessed participants' attitudes towards self-management (questions B1-9). Participants were asked to mark their agreement or disagreement with statements on a four-point Likert scale.

Questionnaire 2: Questionnaire 2 assessed participants' attitudes towards self-management concepts. This was done by asking participants to mark answers ranging from "strongly disagree" to "strongly agree" on a four-point Likert scale.

Interviews: The interviews (conducted by a research assistant) explored participants' attitudes towards self-management and the use of a self-management approach as an intervention method. During the interviews, participants were guided by open-ended questions about perceptions of self-management that were developed by the research team (Table 1). Interviews were conducted at a mutually acceptable venue, audio recorded and later transcribed word for word. Each interview lasted approximately an hour.

\section{Reflexivity}

The research team comprised three physiotherapy students in their final year of study, two supervisors with research experience in self-management in the field of physiotherapy 


\section{Table 1: Questions used in semi-structured interviews}

1. What do the words "self-management" mean to you?

2. How have your views about self-management changed over time?

3. What barriers do you think surround patient selfmanagement?

4. What things do you need to help you facilitate patient selfmanagement skills?

5. What do you see as being your role in patient selfmanagement?

6. What, in your opinion, are the positives and negatives about including patient self-management in rehabilitation settings?

7. Can you give me an example of a time you have helped a patient to self-manage? How did that go? What were the lessons you learned?

( $\mathrm{LH}$ and CS) and a research assistant with a background in physiotherapy. We were aware that our own professional backgrounds may influence the way we interpreted the data. Prior to conducting analysis on the raw data, open discussions were held to identify our own beliefs and reflections. These were written down, put to one side and were referred back to throughout various stages of the analysis process. This was done to ensure that the voices of all participants were captured and portrayed as accurately as possible (Dowling, 2006).

\section{Data analysis}

All qualitative and quantitative data were anonymised. The timing of the analysis was sequential, i.e. beginning with the qualitative analysis followed by the quantitative. Interview data were analysed first to identify common themes and attitudes. Quantitative data were then explored to reveal patterns that supported the resulting themes from the qualitative data (Morse \& Cheek, 2014).

Qualitative analysis was conducted using the General Inductive Approach (Thomas, 2006). Categorical analysis was conducted for all three interview transcripts by the three student researchers. This was achieved by highlighting passages of the transcript which provided insight into the participant's attitudes towards self-management, and describing the selected passage with a code. Multiple codes were then collated and collapsed to a specific category. Once all the student researchers had coded each interview, the three researchers discussed and debated their analysis with the two supervisors (LH, CS). The categories of each researcher were then combined to create an overall consensus of the main categories. The resulting categories were further analysed and collapsed into the resulting themes.

Questionnaire data were entered into Microsoft Excel 2013 and descriptively analysed (frequencies, means and standard deviations).

\section{RESULTS}

The findings from the semi-structured interviews and the questionnaires are presented below. The total participant sample $(n=51)$ comprised HCPs from different fields of practice: 19 nurses, six physiotherapists, six occupational therapists, five social workers, two dietitians, one occupational therapy assistant, one speech-language therapist, one hospital liaison officer, one physiotherapy assistant and one community stroke advisor. Three participants (P1, P2, P3) were purposively selected for interview.

Analysis of interview data revealed three themes concerning the beliefs, attitudes and experiences of HCPs surrounding self-management. The main overarching theme - "Integrating the Self-Management concept into Practice" - encompasses factors contributing towards, and including, understanding the principles behind self-management and the ability for HCPs and patients to carry out these principles in their own practice or daily life. Two major contributors to this overarching theme were "education" and "facilitators of empowerment". Education included patients' awareness of their rights, their condition and their role in their own recovery that affect the process of linking the concept of self-management to actions of self-management. Participants recognised that facilitators of empowerment are pivotal in carrying out tasks of self-management. Empowerment is seen as a driver of self-efficacy which enables patients' decision-making.

Qualitative findings

Integrating the self-management concept into practice: Participants were familiar with the concept of self-management prior to the training and had varying degrees of experience using the concept in practice. One interviewee shared the point of view that the concept had merit and the potential to be beneficial: "Self-management is a good concept and it should work in the idealistic world." (P3)

However, participants felt there were factors that influence the application of self-management into their own clinical practice. Participants identified that the setting or phase of rehabilitation impacted their ability to implement self-management.

Resources vary in different environments and settings, and the most important and common resource identified across all participants was time. For example, the length of stay for a patient in an acute setting is much shorter compared to that of the rehabilitation setting because "when you are going through an acute medical phase, is very difficult because usually medication, treatment options and diagnostics are pre-set anyway." (P1)

Questionnaire data showed that all three interviewees felt that a self-management approach takes more time. In addition, participants felt generational factors and the highly medicalised environment of some settings meant that self-management was a concept that may not only take time to administer but would take time to be accepted and widely used in rehabilitation and acute settings: "I don't know if it's going to be something you can teach them [patients] over a short period of time." (P3)

Participants also felt that self-management was not a suitable approach for every patient, and all participants mentioned the challenges that surround stroke-related cognitive impairments. In particular, the communication between the multi-disciplinary team (MDT) and the patient was identified as a challenge. Participants felt there were more opportunities for the patients and their families to communicate with HCPs in rehabilitation 
settings as opposed to the acute ward setting because "patients in rehab probably have got more control about where they are going. " (P1)

Throughout all the interviews, emphasis was placed on both the HCPs' and the patients' ability to perceive and understand the importance of self-management. Reportedly, a deeper and more comprehensive understanding of the self-management concept translates to better use, as articulated by one participant: "I think if I don't believe in something 100\% that it's going to be hard for me to use it." (P3)

Participants referred to their own personal values, beliefs and culture as well as patient factors, such as age and generation, as challenges impacting their ability to incorporate a selfmanagement approach. Making the point that explaining how exposure to the concept of self-management earlier in life may encourage the patient to be more accepting of the idea later in life when the chances of significant health events increases, one participant said:

People in their 40s and 50s now, if they start to be exposed to this kind of concept more and more, hopefully when they get to their 70s or 80s, when they have a stroke, they will be more acceptable to this sort of concept. (P3)

Whilst the concept of self-management was familiar to our sample, participants described barriers to putting the concept into practice. Whilst the participants talked about time and context as organisational barriers to putting self-management into practice, we identified two themes that described core values of the sample that could act as a barrier ("education") or enabler ("facilitating empowerment").

Education: Participants felt that education was a key component in facilitating self-management, referring to both their own education as HCPs and the education provided to the patient by the HCP: "But I think educational information is the cornerstone on how they can move forward with this. I don't think you can make decisions with a lack of educational information." (P1)

Participants strongly expressed their responsibility to offer education as a "cornerstone" of rehabilitation. For example:

We should be responsible for promoting that awareness. I suppose that we've got the gatekeeping abilities to notify people about that, and it should be a big component of our day-to-day work. That they are allowed... oh, that they are advised, that you know, they can make decisions about where they are going next, what their personal goals are. (P1)

Whilst participants felt that patients were better educated in regard to their rights to care, they felt that patients were not familiar with the self-management approach and still relied on HCPs to lead their rehabilitation. When also referring to patient education, participants felt that, overall, patients have a greater understanding nowadays of their rights to certain care. This reportedly helps to give patients the confidence to play a greater part in the decision-making progress: "Now they've got a greater awareness of their decision-making capabilities within their care itself." (P1)
Barriers such as a patients' perception and awareness of selfmanagement, and lack of understanding of their condition were identified. Participants felt sometimes patients and their families had little understanding of their condition, making communicating the idea of self-management more difficult: "The other thing is health literacy... some of the patients, even with their families, you can't reason them through." (P3)

Patients' perception of self-management was deemed by interviewees to be a barrier as well. Interviewees reported that patients' individual culture made it hard for the selfmanagement approach to be successful as core values could differ: "Someone has already lived their life 70 to 80 years in that kind of way and now you're asking them to change, which is hard thing." (P3)

All participants identified post-stroke cognitive impairments as having an impact on a patient's ability to receive and understand the given information.

Every stroke is different and every person that has had a stroke is different so you have to manage everyone differently, not that they're not all the same, they're not. You can't say that they're all eggs in a basket and that you can do this with them - it has to be individually tailored for the person. (P2)

Our sample felt that education of patients and HCPs is pivotal in linking the process of understanding the concept of selfmanagement and applying it in practice. Tailored education has been highlighted as crucial for understanding. Along with education, individualised facilitation of empowerment has proven to be another theme contributing to the integration of self-management into practice.

Facilitating empowerment: Participants' identified that facilitating empowerment had a large role in patients contributing to the management of their condition: "So its behaviour, knowledge, empowering people to make decisions for themselves." (P1)

Empowerment was seen as a means of encouraging patients to feel in control and facilitate their progress on their own terms:

"They are engaged to do an activity or go through a certain process at their own speed as independently as possible." (P1)

Participants identified the importance of individualising and tailoring information and care as stroke affects people differently. As people react differently to life events, participants felt that it would be ineffective to apply one style or supply one set of information to all patients, as everyone is at different stages and on different pathways of recovery: "The cognitive impairment and also the emotional changes that they've gone through, they sometimes react differently... than what they would've done under normal circumstances." (P2)

In addition to providing a way of individualising the patient role in their own care, participants felt they had a role in motivating patients as well as guiding and supporting them. Evident across interviews was the need for collaboration and working with the patient themselves, their family and the MDT in order for a self-management approach to be successful. "I think that the 
patient should have greater access to what goes on within the MDT meetings... There is the need for a greater cohesive picture about what is going on with their plan of care." (P1)

Participants felt that a collective approach may also contribute to providing a tailored approach to facilitating empowerment. Tailored approaches for providing both education and facilitators of empowerment seem to be most beneficial when integrating the concept into the practice of self-management.

\section{Questionnaires}

In this set of results, we present findings from the questionnaires $(n=43)$ related to the key themes as presented above (see Tables 2-4).

Questionnaire 1, Part 1 ( $A \& B$ ): The first questionnaire explored (A), whether HCPs felt able to implement the core self-management principles of goal setting, reflection, problemsolving, resource utilisation, knowledge, self-discovery, taking action; and (B), whether the healthcare professional actually implemented these principles into their practice. A higher score (rated on a 0-4 scale) indicated higher ability and higher actual implementation. Overall, the data in questionnaire 1 part 1 $(A \& B)$ indicates that participants' confidence in their ability to perform self-management concepts is greater than the frequency they actually apply and implement the concept or task into their practice as an HCP. For example, whilst $74 \%$ of participants felt that they could at least sufficiently ask stroke survivors or find out from their family or friends about what is most important to them right now ("patient-centred goal setting"), only $28 \%$ of participants reported that they always did so in their practice.

In 14/15 questions in questionnaire 1, part 1 (B), at least $20 \%$ of HCPs reported they "frequently" agreed to the statement. This shows that almost all of the actions were being carried out more than occasionally by HCPs.

Totals were gathered for each participant based on the responses they gave for part 1 of questionnaire 1 ; the higher the total score, the greater affinity to the understanding and implementation of the principles of self-management. These scores revealed that the average scores for HCPs' perceptions on the concepts of self-management they can do (48.5) is greater than the frequency they actually do it (46.6). However, both average scores had large standard deviations - 20.5 and 16.8 respectively. Furthermore, totals for participants' scores were placed into score brackets (0-15, 16-30, 31-45, 46-50 and 51-75). The highest score possible was 75 , which indicated a high confidence in capability of self-management principles. Similar to the pattern of the average scores, $70 \%$ of participants felt highly confident in their ability to apply self-management principles (score bracket $51-75$ ), whereas only $50 \%$ of participants felt they actually did this a majority of the time in practice (score bracket 51-75).

Utilising resources is key to supporting self-management, and yet, whilst $67 \%$ of participants reported that they had "sufficient" or "good" confidence in their ability to ask family or friends how they feel and who they could ask for support if needed, only $16 \%$ of HCPs always did so in practice. Although
$81 \%$ of participants felt they could ask family/friends how much confidence they have in their abilities to support their loved one, only $9 \%$ reported that they always did this.

Questionnaire 1, Part 2: This part of questionnaire 1 gauged the attitudes of HCPs towards self-management. Participants were more positive about the concept if they tended to agree with the questions. Sixty-three percent of participants agreed that they knew how to engage cognitively impaired stroke survivors in their care or other activities.

Questionnaire 2: Questionnaire 2 explored attitudes towards self-management concepts. Similar to part 2 of questionnaire 1 , if participants agreed with statements, they were deemed to hold a more positive attitude towards the self-management approach.

About half of participants (51\%) felt that self-management had already been part of their MDT approach, and 63\% were confident in their individual ability to promote the benefits of self-management.

The vast majority (74\%) believed that self-management is not about patients complying with HCP advice, but over half (56\%) of the participants often experienced that patients did not want to self-manage as they assumed that HCPs are the experts.

About half (53\%) reported that they were unaware of ways to measure the impact of supporting self-management post-stroke and felt that they did not know any self-management tools that could be used by patients with stroke and their families (51\%).

It is noteworthy that $52 \%$ of participants felt that a selfmanagement approach would take more time in the clinical setting, and yet $74 \%$ of participants disagreed with the following statement: "I have too many other priorities and demands to get patients to self-manage."

\section{DISCUSSION}

This study aimed to explore the attitudes, knowledge and beliefs of HCPs towards stroke self-management. HCPs in our study were mostly positive about self-management but there were mixed opinions on the practicality of the concept. These perceptions were reflected by the three interview participants and the themes that were revealed through analysis of these data. The overarching theme was the integration of the concept of self-management into practice. Two further themes - education and facilitating empowerment - contributed to the overarching theme. These two themes raised barriers in terms of entrenched expectations from both HCPs and patients (education) and enablers in terms of facilitating empowerment. These findings were supported by the data in questionnaire 1 , where the majority of participants felt their ability to use self-management principles was high, but then only half of participants actually applied these principles frequently in practice.

Participants felt there were factors that influenced the application of the self-management concept into their practice. Participants identified the positives of using a self-management approach but conflict was evident between these recognised benefits and organisational barriers, such as time and context. 


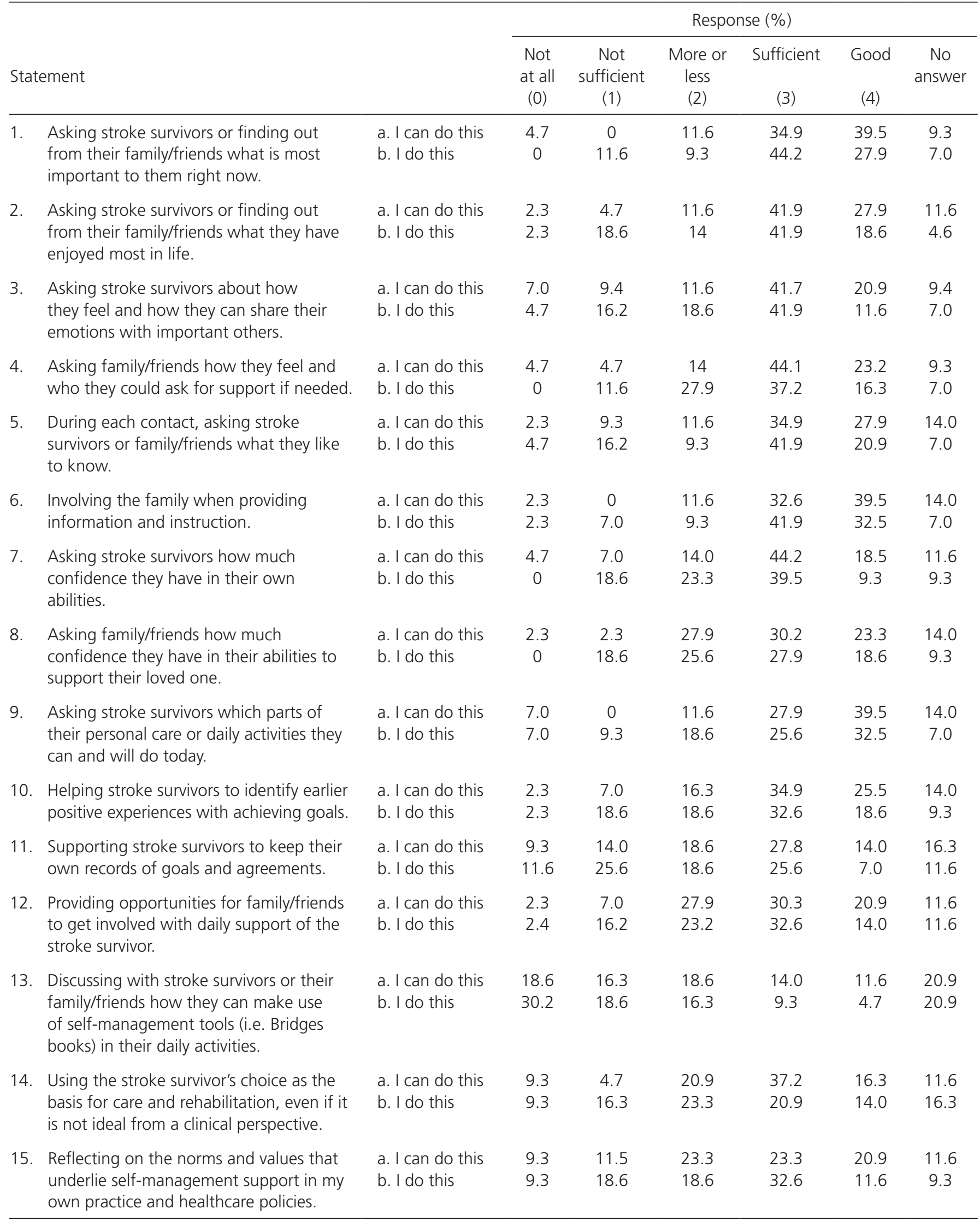




\begin{tabular}{|c|c|c|c|c|c|c|c|}
\hline \multirow[b]{2}{*}{ Statement } & \multicolumn{7}{|c|}{ Response (\%) } \\
\hline & $\begin{array}{l}\text { Strongly } \\
\text { disagree } \\
\text { (1) }\end{array}$ & $\begin{array}{c}\text { Disagree } \\
\text { (2) }\end{array}$ & $(2.5)$ & $\begin{array}{l}\text { Agree } \\
\text { (3) }\end{array}$ & (3.5) & $\begin{array}{l}\text { Strongly } \\
\text { agree } \\
\text { (4) }\end{array}$ & $\begin{array}{c}\text { No } \\
\text { Answer }\end{array}$ \\
\hline $\begin{array}{l}\text { 1. Our MDT has a shared understanding } \\
\text { and agreement about working in a } \\
\text { person-centred way that includes } \\
\text { self-management support. }\end{array}$ & 0 & 16.3 & 0 & 55.8 & 0 & 16.3 & 11.6 \\
\hline $\begin{array}{l}\text { 2. I feel worried not to have all the } \\
\text { answers for stroke survivors and their } \\
\text { families/friends. }\end{array}$ & 7.0 & 27.9 & 0 & 41.9 & 0 & 9.2 & 14.0 \\
\hline $\begin{array}{l}\text { 3. I feel confident to support stroke } \\
\text { survivors and their families/friends to } \\
\text { build insight into the effects of the } \\
\text { stroke through supportive failure. }\end{array}$ & 2.3 & 27.9 & 2.3 & 46.5 & 0 & 4.7 & 16.3 \\
\hline $\begin{array}{l}\text { 4. I feel supported by my organisation } \\
\text { to provide self-management support } \\
\text { in an acute setting. }\end{array}$ & 0 & 30.2 & 0 & 37.2 & 0 & 7.0 & 25.6 \\
\hline $\begin{array}{l}\text { 5. I know how to engage stroke } \\
\text { survivors in their care or other } \\
\text { activities when they have low mood. }\end{array}$ & 4.7 & 20.9 & 0 & 58.1 & 0 & 4.7 & 11.6 \\
\hline $\begin{array}{l}\text { 6. I know how to engage stroke } \\
\text { survivors in their care or other } \\
\text { activities when they have } \\
\text { communication problems. }\end{array}$ & 7 & 23.2 & 0 & 53.5 & 0 & 4.7 & 11.6 \\
\hline $\begin{array}{l}\text { 7. I know how to engage stroke } \\
\text { survivors in their care or other } \\
\text { activities when they have cognitive } \\
\text { problems. }\end{array}$ & 4.7 & 20.9 & 0 & 48.8 & 0 & 11.6 & 14.0 \\
\hline $\begin{array}{l}\text { 8. I feel confident that stroke survivors } \\
\text { and their families/friends can } \\
\text { manage their daily life well after } \\
\text { discharge. }\end{array}$ & 2.3 & 34.9 & 0 & 34.9 & 2.3 & 9.3 & 16.3 \\
\hline 9. I find my work enjoyable. & 0 & 0 & 2.2 & 58.4 & 0 & 28.0 & 11.4 \\
\hline
\end{tabular}

Note: MDT, multi-disciplinary team 


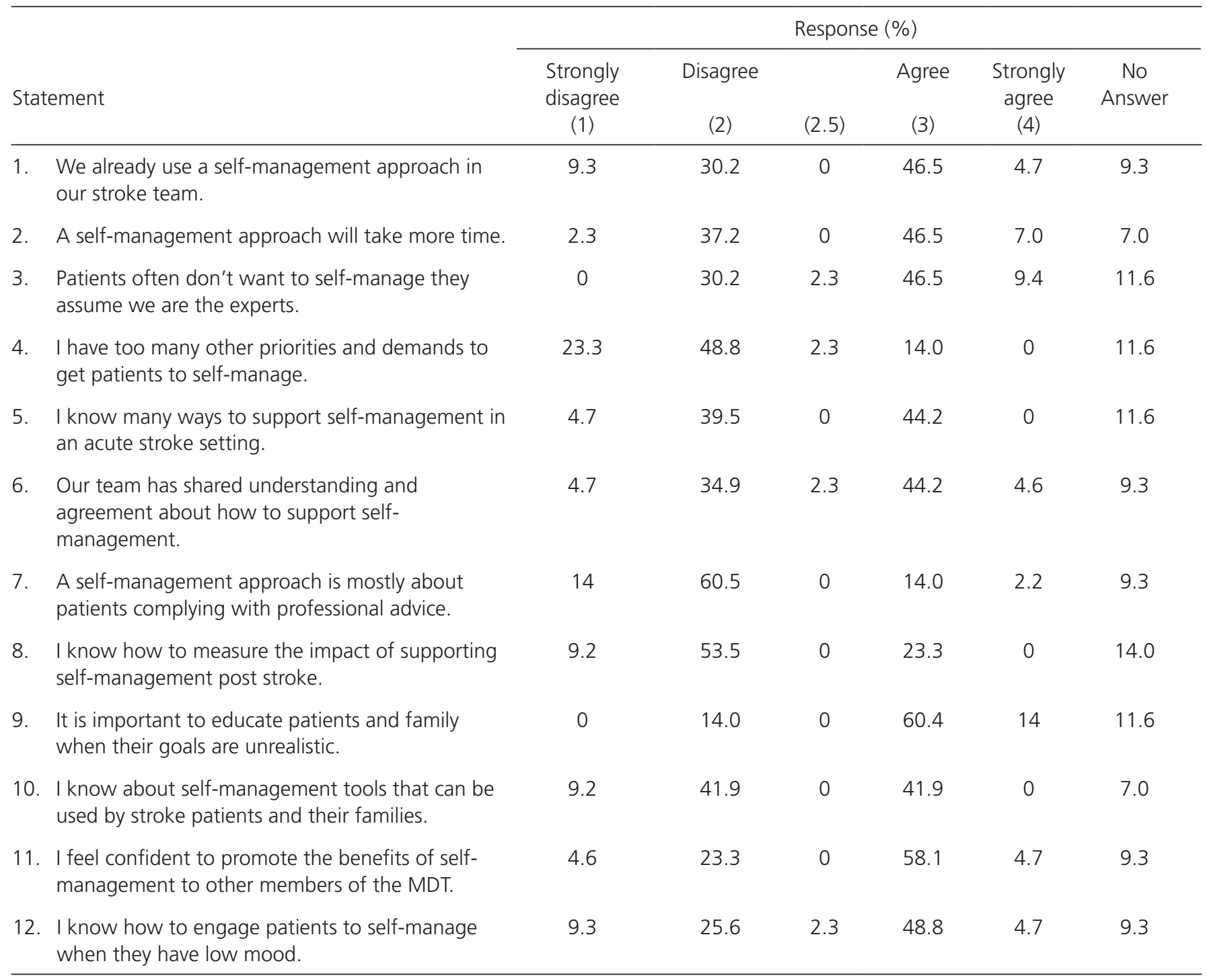

Note: MDT, multi-disciplinary team

Overall, participants in our study felt that a self-management approach would take more time, which is consistent with a study by Jones and Bailey (2013). Although self-management skills, such as goal setting, self-discovery and reflections, are skills that have to be developed over time, HCPs can easily incorporate opportunities for patients to develop and practice these skills within their daily lives and rehabilitation. For example, for "self-discovery", asking the patient how they felt their last activity went (e.g. a walk down the corridor); and for "goal setting", what small thing they would like to improve on next time (they engaged in that activity) (Jones et al., 2013).

Leading on from the concept of self-management requiring time, participants felt it was going to take time to change the conventional medical management and medicalised environment of the acute setting, with the majority of participants feeling that patients often do not want to self-manage as they assume HCPs were the experts. Similarly, in a study by Norris and Kilbride (2014), HCPs felt that during the period of acute care, stroke survivors are expected to be a "passive recipient of care" (p.34). Other studies looking at HCP perspectives have shown similar organisational factors which were perceived as barriers to self-management (Sadler, Wolfe, Jones, \& McKevitt, 2017; Satink et al., 2015). These factors include the current biomedical stroke rehabilitation model and medical-lead treatment in the acute setting, and time pressures due to quick discharge from hospitals. Participants in our study felt it may take some generations for self-management to become widely used and that current generations may not accept the approach. In contrast, the point was made that generations growing up now with exposure to media and technology are more aware of new concepts and, therefore, may be more accepting of the idea of self-management. These ideas surrounding the challenges of implementing self-management are based on the assumption from HCPs that self-management is largely about didactic patient education rather than about changing the way they personally work with patients. The Bridges SSMP discusses self-management as being about what HCPs say and do with 
patients to support patient self-management, and helping patients learn the skills and principles of self-management (Jones et al., 2016).

Once again, supporting the idea that HCPs may view selfmanagement as didactic education, interviewed participants reflected that patient education is important and a key facilitator in the self-management process. In contrast, questionnaire data showed that the majority of participants agreed that self-management is not about patients complying with HCPs' advice. Rather, self-management is a process of partnership between HCPs and patients, enabling individuals to have an active role in the management of their life after stroke. Foster, Taylor, Eldridge, Ramsay, and Griffiths (2007) highlight the importance of the difference between self-management interventions and general delivery of education to patients from HCPs. Education is a core component of an HCPs' skills, for example, required competencies of physiotherapists in New Zealand include patient education but not self-management (Physiotherapy Board of New Zealand, 2015). This educational approach defines patient problems from the perspective of the HCP and is limited to giving information (Bodenheimer, 2002). In some circumstances, didactic education is necessary (de Silva, 2011). For example, teaching patients with asthma how to use inhalers and patients with diabetes how to test their blood glucose levels. Self-management, however, goes beyond didactic education, and encourages individuals to have an active role in the management of their condition and identify their own problems, goals and actions (Bodenheimer, 2002).

This raises the question about the HCPs' understanding of the self-management concept, even following self-management training. The majority of our participants did not respond when asked about their ability to discuss with stroke survivors or their families how they can make use of self-management tools, and additionally, they reported that they never did this in practice. This may indicate that HCPs require a greater understanding of self-management concepts in order to properly apply them. Practicing a concept that is not fully understood means HCPs may be defaulting to patient education as self-management. As mentioned earlier, in our study it appears that the HCPs viewed self-management as patient education or simply teaching patients about the concept, as opposed to the HCP changing their approach with patients. Language used by interview participants illustrates this prioritising of education, with one participant referring to self-management as "allowing" and "advising" patients about their decisions and goals (P1). However, traditional didactic education is not an effective means of increasing a patient's self-efficacy to self-manage their stroke recovery (Jones, 2006). As stated in Bandura's self-efficacy theory, increasing self-efficacy can be achieved through improving a patient's confidence in their ability to perform tasks and increasing their expectations of achieving their goals. These can be facilitated through a self-management approach (Bandura, 1977). Understanding the concept of selfmanagement and developing this understanding so it can be applied in practice may bridge the gap between the concept and its applicability to practice.
In questionnaire 1, a vast majority of the participants reported "always" carrying out many of the tasks and concepts they were questioned about. This may indicate that with continued training and exposure to self-management, participants will begin to "always" use the concept. Questionnaire data showed that when participants thought they were "good" at a task or concept, they were more likely to "always" carry out this task. Building on the previous point, with continued use of self-management in their practice, HCPs' self-efficacy and confidence when using this approach with stroke survivors is likely to increase. This finding is consistent with the models found within the Social Cognitive Theory, as self-efficacy is based on confidence in one's ability to execute the task, which then leads to a more venturesome behaviour that is within reach to their capabilities (Mark \& Paul, 2005).

Challenges surrounding implementing self-management with a patient with cognitive impairments was mentioned by all interview participants in our study, supporting the findings of Satink et al. (2015). Our qualitative findings, however, were in contrast to the questionnaire data where the majority of participants felt they knew how to engage stroke survivors with cognitive problems in their care. It is positive that participants feel they are able to communicate without issue as this is crucial in a concept that focuses on empowering the patient, but this finding does highlight the need to explore alternative strategies for self-management for stroke survivors with cognitive impairments.

Participants in our study reflected on the importance of facilitating empowerment in patients when implementing self-management. Empowering patients was seen as a way of helping them to feel in control of the management of their condition and to facilitate progress around goals. A systematic review investigated stroke survivors' attitudes around stroke rehabilitation, and the need for regaining control and assuming responsibility was similarly identified as a key theme (Peoples, Satink, \& Steultjens, 2011). Interestingly, most participants in our study felt that it was important to educate patients and their families when their goals were perceived by the HCP as being unrealistic. Once again, this highlights that participants in our study have not yet gained an in-depth understanding of the principles surrounding self-management, in that they tend to default to principles of didactic education. Jones et al. (2016) defines the seven key principles of the Bridges SSMP and discusses the process of empowering patients and encouraging small steps towards longer term goals as opposed to discouraging unrealistic goals.

Participants in our study felt confident in their ability to involve the patient and their family members in their care. Our interview findings support those of a recent study that found collaboration between the patient, their family and the MDT is a key component of self-management support (Sadler et al., 2017).

\section{Strengths and Limitations}

We acknowledge the limitations of this study. Firstly the small sample size in both the interviews and questionnaires may not be representative of all perspectives. The small number 
of interview participants in our qualitative data may not have captured the overall perceptions of the cohort. Another limitation is that our questionnaires were only carried out prior to self-management training, and not both before and after training. However, strengths of the study were that we included a variety of health professionals working in both acute and community settings. Further strengths were in the mixed methods design which gave breadth and depth to the study.

\section{CONCLUSION}

Overall, this study has shown that HCPs have positive attitudes towards the concept of self-management but there were mixed opinions on the practicality of this concept. Barriers and challenges have been highlighted which may be an avenue to improving the effectiveness of introducing and implementing this concept into the healthcare system. This study has a number of implications for practice and future research. Before HCPs can successfully support stroke survivors with their self-management, they first need to have an in-depth understanding of self-management principles. This may mean HCPs need to be supported in further training and encouraged to continually practice and apply the principles of selfmanagement in their practice. HCPs may default to the more familiar didactic education approach when they do not have a deep understanding of the principles of self-management. Therefore, HCPs may need more time to learn the principles of self-management, but also time to use these principles on themselves. For example, learning and using a new concept may be more successful if HCPs are able to develop their own mastery by using small steps and goals, and undertaking self-reflection. By understanding through reflection how selfmanagement principles can be used for their own personal growth, HCPs may be more likely to understand the benefits of self-management for stroke survivors. Future research investigating the attitudes of HCPs after their experience of using self-management in practice for a period of time is warranted. For self-management to become a mainstream concept, especially in the acute setting, continued work and research to explore the barriers to supporting self-management is needed.

\section{KEY POINTS}

1. HCPs appear to have positive attitudes towards the concept of patient self-management but mixed opinions on the practicality of embedding this into practice.

2. Supporting stroke survivors with self-management requires an in-depth understanding of the principles of selfmanagement as well as practice in implementing them.

3. HCPs may default to didactic education, if this is more familiar to them than the principles of self-management.

\section{DISCLOSURES}

We acknowledge the Physiotherapy New Zealand Scholarship Trust Fund for funding the larger project, of which our student project was a small component. The authors report no conflict of interest.

\section{PERIMISSIONS}

Ethical approval was gained from the Health and Disability Ethics Committees (Ethics ref: 18/STH/93).

\section{ACKNOWLEDGEMENTS}

We are grateful to the participants and the research assistant for involvement in this study. We also acknowledge the other researchers of the larger project: Associate Professor William Levack, Professor Denise Taylor, Dr Lynne Clay and Professor Fiona Jones.

\section{ADDRESS FOR CORRESPONDENCE}

Professor Leigh Hale, School of Physiotherapy, University of Otago, PO Box 56, Dunedin, 9054, New Zealand. Telephone: +64 3479 5425. Email: leigh.hale@otago.ac.nz.

\section{REFERENCES}

Bandura, A. (1977). Self-efficacy: Toward a unifying theory of behavioral change. Psychological Review, 84(2), 191-215. https://doi. org/10.1037/0033-295X.84.2.191

Barlow, J., Wright, C., Sheasby, J., Turner, A., \& Hainsworth, J. (2002). Self-management approaches for people with chronic conditions: A review. Patient Education and Counselling, 48(2), 177-187. https://doi. org/10.1016/S0738-3991(02)00032-0

Bodenheimer, T. (2002). Patient self-management of chronic disease in primary care. JAMA, 288(19), 2469-2475. https://doi.org/10.1001/ jama.288.19.2469

de Silva, D. (2011). Evidence: helping people help themselves: A review of the evidence considering whether it is worthwhile to support selfmanagement. London: The Health Foundation. Retrieved from https:// www.health.org.uk/sites/default/files/HelpingPeopleHelpThemselves.pdf

Dowling, M. (2006). Approaches to reflexivity in qualitative research. Nurse Researcher, 13(3), 7-21. https://doi.org/10.7748/nr2006.04.13.3.7.c5975

Foster, G., Taylor, S.J., Eldridge, S., Ramsay, J., \& Griffiths, C.J. (2007). Selfmanagement education programmes by lay leaders for people with chronic conditions. The Cochrane Database of Systematic Reviews, Oct 17;(4):CD005108. https://doi.org/10.1002/14651858.CD005108.pub2

Jones, F. (2006). Strategies to enhance chronic disease self-management: How can we apply this to stroke? Disability and Rehabilitation, 28(13-14), 841-847. https://doi.org/10.1080/09638280500534952

Jones, F., \& Bailey, N. (2013). How can we train stroke practitioners about patient self-management? Description and evaluation of a pathway wide training programme. European Journal for Person Centered Healthcare, 1(1), 246-254. https://doi.org/10.5750/ejpch.v1i1.660

Jones, F., Gage, H., Drummond, A., Bhalla, A., Grant, R., Lennon, S., .. Liston, M. (2016). Feasibility study of an integrated stroke selfmanagement programme: a cluster-randomised controlled trial. BMJ Open, 6(1), e008900. https://doi.org/10.1136/bmjopen-2015-008900

Jones, F., Mandy, A., \& Partridge, C. (2009). Changing self-efficacy in individuals following a first time stroke: preliminary study of a novel selfmanagement intervention. Clinical Rehabilitation, 23(6), 522-533. https:// doi.org/10.1177/0269215508101749

Jones, F., Pöstges, H., \& Brimicombe, L. (2016). Building Bridges between healthcare professionals, patients and families: A coproduced and integrated approach to self-management support in stroke. NeuroRehabilitation, 39(4), 471-480. https://doi.org/10.3233/NRE-161379

Jones, F., Riazi, A., \& Norris M. (2013). Self-management after stroke: Time for some more questions? Disability and Rehabilitation, 35(3), 257-264. https://doi.org/10.3109/09638288.2012.691938 
Lorig, K.R., \& Holman, H.R. (2003). Self-management education: History, definition, outcomes, and mechanisms. Annuals of Behavioral Medicine, 26(1), 1-7. https://doi.org/10.1207/S15324796ABM2601_01

Mark, C., Paul, N (2005). Predicting health behaviour. Berkshire, England: McGraw-Hill Education.

Morse, J.M. (2009). Mixing qualitative methods. Qualitative Health Research, 19(11), 1523-1524. https://doi.org/10.1177/1049732309349360

Morse, J.M., \& Cheek, J. Making room for qualitatively-driven mixedmethod research. Qualitative Health Research, 24(1), 3-5. https://doi. org/10.1177/1558689810390217

Norris, M., \& Kilbride, C. (2014). From dictatorship to a reluctant democracy: stroke therapists talking about self-management. Disability and Rehabilitation, 36(1), 32-38. https://doi.org/10.3109/09638288.2013.77 6645

Peoples, H., Satink, T., \& Steultjens, E. (2011). Stroke survivors' experiences of rehabilitation: A systematic review of qualitative studies. Scandinavian Journal of Occupational Therapy, 18(3), 163-171. https://doi.org/10.3109/ 11038128.2010.509887

Physiotherapy Board of New Zealand. (2015). Physiotherapy practice thresholds in Australia \& Aotearoa New Zealand. Retrieved from https:// www.physioboard.org.nz/sites/default/files/PhysiotherapyPractice $\% 20$ Thresholds3.5.16.pdf

Rajsic, S., Gothe, H., Borba, H.H., Sroczynski, G., Vujicic, J., ... Siebert, U. (2019). Economic burden of stroke: A systematic review on post-stroke care. European Journal of Health Economics, 20(1), 107-134. https://doi. org/10.1007/s10198-018-0984-0

Sadler, E., Wolfe, C.D.A., Jones, F., \& McKevitt, C. (2017). Exploring stroke survivors' and physiotherapists' views of self-management after stroke: A qualitative study in the UK. BMJ Open, 7(3), e011631. https://doi. org/1010.1136/bmjopen-2016-011631

Satink, T., Cup, E.H.C., de Swart, B.J.M., \& Nijhuis-van der Sanden, M.W.G. (2015). Self-management: Challenges for allied healthcare professionals in stroke rehabilitation - a focus group study. Disability and Rehabilitation, 37(19), 1745-1752. https://doi.org/10.3109/09638288.2014.976717

Thomas, D.R. (2006). A General Inductive Approach for analyzing qualitative evaluation data. American Journal of Evaluation, 27(2), 37-46. https://doi. org/10.1177/1098214005283748

Valery, L.F., Bo, N., \& George, A.M. (2017). Global burden of stroke. Circulation Research, 120(3), 437-438. https://doi.org/10.1161/ CIRCRESAHA. 116.308413 